\title{
Management of Multi-Casualty Incidents in Mountain Rescue: Evidence-Based Guidelines of the International Commission for Mountain Emergency Medicine (ICAR MEDCOM)
}

\author{
Marc Blancher, ${ }^{1,2}$ François Albasini, ${ }^{2,3}$ Fidel Elsensohn, ${ }^{4}$ Ken Zafren, ${ }^{4-6}$ Natalie Hölzl, ${ }^{7}$ Kyle McLaughlin, ${ }^{8,9}$ \\ Albert R. Wheeler, III, ${ }^{10,11}$ Steven Roy, ${ }^{12}$ Hermann Brugger, ${ }^{13}$ Mike Greene, ${ }^{14}$ and Peter Paal ${ }^{15}$
}

\begin{abstract}
Blancher, Marc, François Albasini, Fidel Elsensohn, Ken Zafren, Natalie Hölzl, Kyle McLaughlin, Albert R. Wheeler III, Steven Roy, Hermann Brugger, Mike Greene, and Peter Paal. Management of multi-casualty incidents in mountain rescue: Evidence-based guidelines of the International Commission for Mountain Emergency Medicine (ICAR MEDCOM). High Alt Med Biol. 19:131-140, 2018.

Introduction: Multi-Casualty Incidents (MCI) occur in mountain areas. Little is known about the incidence and character of such events, and the kind of rescue response. Therefore, the International Commission for Mountain Emergency Medicine (ICAR MEDCOM) set out to provide recommendations for the management of MCI in mountain areas.

Materials and Methods: Details of MCI occurring in mountain areas related to mountaineering activities and involving organized mountain rescue were collected. A literature search using (1) PubMed, (2) national mountain rescue registries, and (3) lay press articles on the internet was performed. The results were analyzed with respect to specific aspects of mountain rescue.

Results: We identified 198 MCIs that have occurred in mountain areas since 1956: 137 avalanches, 38 ski lift accidents, and 23 other events, including lightning injuries, landslides, volcanic eruptions, lost groups of people, and water-related accidents.

Discussion: General knowledge on MCI management is required. Due to specific aspects of triage and management, the approach to MCIs may differ between those in mountain areas and those in urban settings.

Conclusions: Mountain rescue teams should be prepared to manage MCIs. Knowledge should be reviewed and training performed regularly. Cooperation between terrestrial rescue services, avalanche safety authorities, and helicopter crews is critical to successful management of MCIs in mountain areas.
\end{abstract}

Keywords: avalanche; emergency medicine; lightning; multi-casualty incidents; mountain rescue; wilderness medicine

\footnotetext{
${ }^{1}$ Department of Emergency Medicine, University Hospital of Grenoble-Alps, Grenoble, France.

${ }^{2}$ The French Mountain Rescue Association (ANMSM), Grenoble, France.

${ }^{3}$ Department of Emergency Medicine, St. Jean de Maurienne Hospital, St. Jean de Maurienne, France

${ }^{4}$ ICAR MedCom, Roethis, Austria.

${ }^{5}$ Department of Emergency Medicine, Stanford University Medical Center, Stanford, California.

${ }_{7}^{6}$ Alaska Mountain Rescue Group, Anchorage, Alaska.

${ }^{7}$ Department of Anesthesiology and Intensive Care Medicine, Klinikum Kempten, Germany.

${ }^{8}$ Department of Emergency Medicine, Canmore, Canada.

${ }^{9}$ Department of Emergency Medicine, University of Calgary, Calgary, Canada.

${ }^{10}$ Department of Emergency Medicine, St John's Medical Center, Jackson, Wyoming.

${ }^{11}$ Search and Rescue Medical Director, Grand Teton National Park, Jackson, Wyoming.

${ }^{12}$ Quebec Secours SAR, Resident Physician Elective in Wilderness Medicine, McGill University, Montreal, Canada.

${ }^{13}$ Institute of Mountain Emergency Medicine, EURAC Research, Bolzano, Italy.

${ }^{14}$ Emergency Medicine Physician, Medical Officer Mountain Rescue England and Wales, Whitehaven, England.

${ }^{15}$ Department of Anesthesiology and Intensive Care, Hospitallers Brothers Hospital, Paracelsus Medical University, Salzburg, Austria.

(C) Marc Blancher et al., 2018; Published by Mary Ann Liebert, Inc. This article is available under the Creative Commons License CC-BYNC (http://creativecommons.org/licenses/by-nc/4.0). This license permits noncommercial use, distribution, and reproduction in any medium, provided the original work is properly cited. Permission only needs to be obtained for commercial use and can be done via RightsLink.
} 


\section{Introduction}

M Ulti-CASUAlty InCIDENTs (MCI) are well described in urban and developed areas, but also occur in mountainous areas. Events such as avalanches, ski lift accidents, sudden floods in canyons, groups of people lost while exposed to a harsh environment, and multiple lightning victims have each resulted in several MCIs in mountain areas (Nicholas and Oberheide, 1988; Carte et al., 2002; Wildner and Paal, 2015). In remote locations, the initial response is likely to be made by first responders with basic training, or by personnel without rescue training, such as bystanders and ski lift operators. A more formal assessment of the incident will take place as soon as organized rescue personnel arrive at the scene.

Compared with an MCI in an urban setting, an MCI in mountain areas may occur in an austere environment that presents additional challenges to the rescue team, such as geographical isolation, exposure to weather extremes, dangerous or difficult terrain, communication difficulties (including limited or absent mobile network or radio connections), the need to rely on mountain rescue extrication techniques such as application of ropes or pulleys, limited human resources and equipment, and specific injuries and illness, for example accidental hypothermia.

This article discusses a generic framework for achieving optimal outcomes for patients and presents levels of evidence for specific aspects of multi-casualty care in mountain rescue. The guidelines provide general principles that can be adapted to the resources available for any mountain incident. This article is divided into three sections, the first outlines principles of disaster medicine that apply to mountain rescue MCIs and highlights those specific to mountain areas. The second section outlines management strategies in three common mountain MCIs: (1) avalanche, (2) lightning accident, and (3) a group of lost people. Finally, recommendations are proposed to enable best practices.

\section{Definition}

An MCI in a mountain area occurs as soon as the number of victims overwhelms or substantially stretches the technical and medical resources of the mountain rescue service (Hammond, 2005; Ben-Ishay et al., 2016; Keim, 2016). An MCI in a mountain area is not rigidly defined by a specific number of casualties. Compared with an urban environment, a lower number of casualties may be considered an MCI because resources are more limited.

\section{Materials and Methods}

The International Commission for Mountain Emergency Medicine (ICAR MEDCOM) convened a group of experts on MCI in mountain areas to develop evidence-based guidelines. MCI scenarios discussed in this work were selected because of their incidence and relevance to mountain rescue.

A literature review was performed using PubMed and the Cochrane database, Web Of Science, and Google Scholar, and the last update was done on June 30, 2017. Only case reports, letters, original articles, and reviews were considered for this search. In PubMed the following key words were used (1) "mass casualty incidents" alone or (2) in combination with "disasters," "disaster medicine," "triage," "mountaineering," "avalanche," "lightning injuries," "skiing," "snow sports." The search was further refined to exclude articles containing "crime," because the «crime» term was used as a separator between urban and mountain MCI. Crime related MCI in mountains do not feature in PubMed. In Google Scholar the search was limited to "mass casualty incidents" in mountain. Only studies involving human casualties and published in English, French, or German were included. To identify as many MCI events in mountain areas as possible, research was also performed using (1) national mountain rescue registries through ICAR MEDCOM members, and (2) Google (i.e., Illicit snowboarding, EM-DAT and lay press entries). Finally, additional research was performed using bibliographies of relevant articles. Studies were included based on their relevance to $\mathrm{MCI}$ in mountains.

Recommendations were developed and graded, based on available evidence strength and quality using the grading system of the American College of Chest Physicians (Table 1) (Guyatt et al., 2006). When no studies existed to provide evidence, the recommendations were based on expert opinion of the authors and of ICAR MEDCOM members. The final draft was discussed and approved by ICAR MEDCOM in October 2017.

\section{Results}

Out of 2049 citations retrieved from all sources of literature research, 221 articles were included in the initial review process. Ultimately, 80 articles (limited to randomized controlled trials, review articles, observational studies, case series, and single reports) were deemed relevant and included in this study (Fig. 1). Overall, 199 MCIs in mountain areas were identified by ICAR members from local or national databases and by the Internet search (Table 2 and Supplementary Tables S1-S3; Supplementary Data are available online at www.liebertpub .com/ham). Most cases were identified through newspapers, open access web sources, and national mountain rescue databases. Around 3518 were people involved in these events; 751 persons were injured and 1036 died. Data were available from nine countries (i.e., Austria, Canada, France, Germany, Italy, Japan, Norway, Switzerland, and the United States). For ski lift

Table 1. Classification Scheme for Grading EVIDENCE (GUYATT ET AL., 2006)

\begin{tabular}{|c|c|}
\hline Grade 1A & $\begin{array}{l}\text { Strong recommendation, high-quality } \\
\text { evidence benefits clearly outweigh risks } \\
\text { and burden or vice versa }\end{array}$ \\
\hline Grade 1B & $\begin{array}{l}\text { Strong recommendation, moderate-quality } \\
\text { evidence benefits clearly outweigh risks } \\
\text { and burdens or vice versa }\end{array}$ \\
\hline Grade 1C & $\begin{array}{l}\text { Strong recommendation, low-quality or very } \\
\text { low-quality evidence benefits clearly } \\
\text { outweigh risks and burdens or vice versa }\end{array}$ \\
\hline Grade $2 \mathrm{~A}$ & $\begin{array}{l}\text { Weak recommendation, high-quality } \\
\text { evidence benefits closely balanced with } \\
\text { risks and burdens }\end{array}$ \\
\hline Grade 2B & $\begin{array}{l}\text { Weak recommendation, moderate-quality } \\
\text { evidence benefits closely balanced with } \\
\text { risks and burdens }\end{array}$ \\
\hline Grade $2 \mathrm{C}$ & $\begin{array}{l}\text { Weak recommendation, low-quality or very } \\
\text { low-quality evidence, uncertainty in the } \\
\text { estimates of benefits, risks, and burden; } \\
\text { benefits, risk, and burden may be closely } \\
\text { balanced }\end{array}$ \\
\hline
\end{tabular}




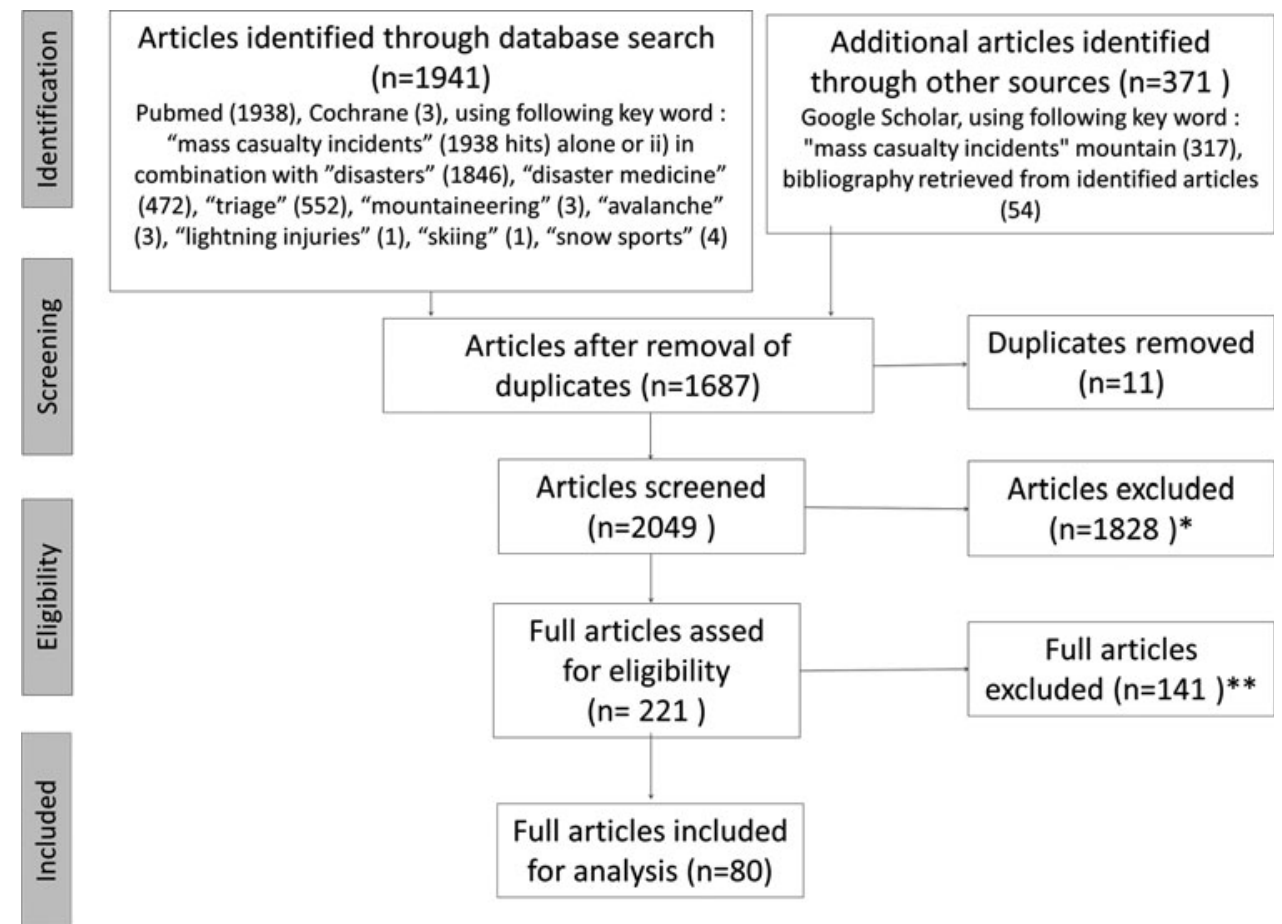

FIG. 1. Flow Chart. *Reasons for first exclusion. (1) New research with exclusion criteria « crime » $(n=1474)$. (2) Articles "out of topic" $(n=354)$. **Reasons for second exclusion. (1) Articles related only to burn injury. (2) Articles related only to in-hospital management. (3) Urban-related MCI case reports (nonwilderness environment). (4) "Point-ofview" articles. MCI, multi-casualty incidents.

accidents data of all contributing countries were available from 1956. For all other mountain MCIs, data were available from 1964 in France and from 1999 in all other contributing countries.

\section{Discussion}

As far as we are aware, this is the first review to focus on MCIs occurring in mountain areas. Collected data highlight the fact that MCIs in mountain areas are expected but uncommon events. ICAR MEDCOM seeks to raise the awareness of MCIs in mountain areas to ensure that rescue teams are prepared for such events. The general principles of handling an MCI in mountain areas should already be under- stood. There are specific environmental and logistical challenges that should be taken into account when managing an MCI in mountain areas.

\section{Principles of $\mathrm{MCl}$ care}

The principles of MCI must be modified in the mountain rescue environment. Even though it is not realistic to be prepared for "every possible disaster," following a generic framework will allow rescue organizations to manage the majority of incidents. At all times rescue teams should prepare by regularly reviewing knowledge, planning, equipment, and training.

Table 2. Mass Casualty Incidents in Mountain Areas According to Cause Since 1954

\begin{tabular}{|c|c|c|c|c|c|}
\hline Type & Events (n) & Dead & Injured & $\begin{array}{l}\text { Number of casualty } \\
\text { per event, median } \\
\text { (interquartile range) }\end{array}$ & Involved \\
\hline Avalanche (recreational activities) & 127 & 313 & 228 & $6(5-10)$ & 1101 \\
\hline Avalanche on habitation & 11 & 234 & 25 & $13(8-40)$ & 738 \\
\hline Ski lift accident & 38 & 335 & 380 & $12(5-19)$ & 1027 \\
\hline Lighting accident & 4 & 5 & 36 & $15(10-17)$ & 53 \\
\hline Lost group of people ${ }^{a}$ & 7 & 0 & 0 & $14(12-21)$ & 119 \\
\hline Water-related accident ${ }^{\mathrm{b}}$ & 6 & 25 & 17 & $6(1-9)$ & 168 \\
\hline Volcano eruption & 1 & 63 & 69 & NA & 250 \\
\hline Others ${ }^{\mathrm{c}}$ & 5 & 16 & 41 & $8(6-9)$ & 62 \\
\hline Total & 199 & 991 & 796 & & 3518 \\
\hline
\end{tabular}

\footnotetext{
a denotes including path cutoff.

${ }^{\mathrm{b}}$ Rafting (3) and canyoning (3).

${ }^{\mathrm{c}}$ Tent fire, tourist train accident, rock and ice slide, landslide, unknown (1).

NA, not applicable.
} 
General principles of multi-casualty care. Important general principles of mass-casualty care are given in Table 3 and will be discussed in more detail here.

Recognition. The accident site should be assessed as soon as possible to determine if the criteria for an MCI are met. If there is an MCI, the specific situation must be explained appropriately to the dispatch center, all relevant rescue organizations, and all participating hospitals (Hammond, 2005).

Recommendation: An MCI should be recognized and the appropriate rescue organizations and hospitals alerted as soon as possible. Recommendation Grade: 1C

Safety. During the initial and subsequent response to an MCI, safety of the rescuers is the highest priority. It is well established that Emergency Medical Service (EMS) personnel and first responders have an increased risk of mortality (Garrison, 2002; Maguire et al., 2002). For example in France, since mountain rescue became a professional service in the late 1950s, 107 rescuers have died during rescue missions (Agresti, 2013). In any rescue mission a risk assessment should be made and a safe and suitable rescue approach should be adopted (Freitas, 2016). In some cases, the response should be delayed until the risk to the rescuers has decreased sufficiently. Safety should not be compromised by external pressure from third parties such as media or government authorities. These principles should also be applied to body recovery, which means that the safety of rescuers should not be put at risk of recovering dead persons (Loriette, 2015).

Recommendation: Safety of the rescuers is the highest priority. Recommendation Grade: 1C

Initial response. The initial priority is to establish a command and control structure. A suitably trained medical provider should be assigned as quickly as possible to make an overall assessment of the situation. This person should communicate with other rescue services and with people who have direct knowledge of the incident, such as witnesses and ski lift operators, to evaluate the nature of the event, hazards, and the number of people involved. The command and control structure must be developed in conjunction with the Initial Incident Commander (Rimstad and Sollid, 2015).

Table 3. Recommendations for the Management of a Multi-Casualty Incident in Mountain Areas

General principles in MCI management

Identifying an MCI. An MCI should be recognized and the appropriate rescue organizations and hospitals alerted as soon as possible.

Assessing safety. Safety of the rescuers is the highest priority.

Initial response. Initial responses should focus on setting up a command and control structure, triage, and rapid life or limbsaving interventions.

Leadership and command. The Medical Commander should be trained in disaster medicine and in mountain rescue. On site, the Medical Commander and leaders of the involved rescue services should be located at the same site to optimize cooperation and all should be easily identifiable.

Ensuring effective communications. An effective communication structure should be implemented to support command and control.

Triage. Efficient triage tools adapted to mountain pathologies should be implemented.

Organizing evacuations. Casualties should be evacuated to a safe area and then transferred to medical facilities appropriate to patient's medical needs.

Identification and traceability. Tools that enable clear identification and tracking of casualties should be available for mountain MCIs.

Learning from experience. MCIs in mountain areas should be analyzed after the fact and recommendations for changes in practice should be proposed and published.

Planning and training. Standard operation procedures should be available, well known, and implemented with regular training involving emergency services.

Specific principles in MCI management in mountain areas

Environmental influence

The use of helicopter. Helicopters with appropriate mountain rescue capabilities are often useful in MCIs. Coordination of helicopter operations is critical.

Communication devices and network.

Management of uninjured people. Uninjured survivors should be considered as casualties at risk in a mountain environment. Psychological trauma.

Specific MCIs in mountain areas

Lightning injuries. Lightning victims who are not breathing and who do not have obvious lethal injuries should be resuscitated before victims who have vital signs.

Avalanches. For a burial time $<35$ minutes, extrication is the first priority and medical care should focus on victims with signs of life until enough resources are available to treat additional victims in cardiac arrest. For a burial time 35 to 60 minutes, no CPR should be started on arrested victims unless enough resources are available. For burial time $>60$ minutes, CPR should only be initiated if the airway is patent. The use of a checklist may improve triage and treatment.

Medical strategy for a group of lost people. The principles of MCI in mountain areas should be applied to groups of trapped or lost people in harsh mountain environments.

CPR, cardio pulmonary resuscitation; MCI, multi-casualty incidents. 
During the initial response, qualified personnel should be allocated to make an initial assessment and to triage the casualties. No advanced medical care should be performed before the whole scene has been assessed and all casualties have been triaged. Only rapid life or limb-saving interventions are indicated at this stage, such as opening an airway or using a tourniquet (FEMA). The next step involves requesting the required resources (Guéant, 2011).

Recommendation: Initial responses should focus on setting up a command and control structure, triage, and rapid life or limb-saving interventions. Recommendation Grade: 1C

Leadership and command. In an MCI in mountain areas, medical coordination is the responsibility of the Medical Commander who should be trained both in disaster medicine and in mountain rescue. Ideally, the medical commander and leaders of the rescue organizations should be located at the same site to establish an action plan for the incident (Rimstad and Sollid, 2015). Frequent updates and joint decision making will further optimize cooperation among rescue organizations. On site, the Medical Commander and leaders of the rescue organizations should be easily identifiable with labeled vests, hats, or badges.

Recommendation: The Medical Commander should be trained in disaster medicine and in mountain rescue. On site, the Medical Commander and leaders of the involved rescue services should be located at the same site to optimize cooperation and all should be easily identifiable. Recommendation class: $1 \mathrm{C}$

Effective communication. It is essential to communicate information and commands clearly among rescue teams, the command post, and the dispatch center. Communication can be particularly challenging in a wilderness environment, where several barriers to efficient communication may exist. It is essential to set up effective "vertical" communications between the different command and execution levels in an MCI rescue mission. At every level of the hierarchy, the commander is responsible for clear communication with the personnel that is "horizontal" communication. The U.S. Incident Command System (ICS) uses the span of control principle. The number of individuals under the control of a single supervisor may range from three to seven subordinates, with five being the ideal number (FEMA, 2017). ICS also uses the "closed loop" principle to ensure that a command is executed. The use of new technologies such as the Internet, if accessible, may also facilitate communication in the future (Chan et al., 2004).

Recommendation: An effective communication structure should be implemented to support command and control. Recommendation Grade: 1C

Triage. Medical management should switch from individual care to triage to optimize the outcome for as many as possible. Mass casualty triage algorithms exist to assist medical providers in prioritizing MCI patients for treatment and transport to use finite resources efficiently (Lerner et al., 2015). Accurately triage of MCI victims may improve survival and outcomes (Frykberg, 2002). A number of triage systems have been described. They all share the principles of simple guidelines and rapid action. Complex medical interventions are not indicated (Kilner et al., 2011). At the completion of triage, every victim should have been labeled to indicate the individual care priority (Arcos Gonzalez et al., 2016). The Medical Commander should have a clear picture of the overall MCI and be able to allocate the resources. Studies comparing triage systems illustrate that performance can be specific to the environment in which they are applied (Sacco et al., 2005; Culley et al., 2014; Vassallo et al., 2014; Price et al., 2016).

Recommendations: Efficient triage tools adapted to mountain pathologies should be implemented. Recommendation Grade: 1B

Organizing evacuation. Evacuating the patients to the appropriate treatment facilities saves lives (Bouzat et al., 2015). In MCI, patient evacuation to appropriate medical facilities should be organized within the regional EMS (Ammons et al., 1988; Nicholas and Oberheide, 1988). Good command and control will enable the Medical Commander to give information on the number and types of casualties who need to be evacuated. This allows allocation of the appropriate hospitals for the patient's needs.

Prenotification allows hospitals to prepare when significant numbers of casualties are to be received in a short period of time. The Medical Commander not only needs to identify the required level of care but also to consider the time to reach appropriate care. In some cases, priority of evacuation may depend upon technical considerations of extrication. In preparation for evacuation from the incident site it may be advisable to move casualties to a casualty clearing area, or areas where they can be sheltered, reassessed, and where further treatment can be provided. Such areas should ideally have access to suitable evacuation facilities such as a helicopter landing site. In an MCI in mountain areas, a casualty clearing station may not be possible or necessary.

Recommendation: Casualties should be evacuated to a safe area and then transferred to medical facilities appropriate to patient's medical needs. Recommendation Grade: 1C

Identification and tracking. In most MCIs, patient identification is challenging. For instance, one patient may be registered twice in two different places, whereas another is not registered at all. Identification tools that are easily visible and attached to the patient are recommended. Tools that include cards, wrist straps, and triage tags, have been implemented by several rescue organizations in many countries. Online electronic systems have been evaluated in urban areas (Marres et al., 2013; Haverkort et al., 2016). Identification and patient tracking is not only a medical issue. Identification is very important from an administrative point of view, particularly when people who are not able to communicate in the local language or children are involved. Given the complexity of an MCI in mountain areas, keeping a written record of the incident and decisions made by the medical commanders is important. Some MCIs will involve enquiries, which may have legal consequences. Access to records made at the time may be important.

Templates for reporting major incidents may facilitate onsite management and aid future investigations. If templates are to be used for registries and research, they should have previously received validation from an Institutional Review Board (Fattah et al., 2013).

Recommendation: Tools that enable clear identification and tracking of casualties should be available for mountain MCIs. Grade: 1B

Learning from experience. MCIs are rare events. Learning from experience of others and building "institutional memory" is crucial. The same errors should not be repeated time 
and again. Prior MCIs reported in the literature highlight the fact that key issues are often the same, namely (1) inadequate collaboration among rescue organizations; (2) lack of planning and training; (3) ineffective communication; (4) lack of leadership and, (5) failure to learn from lessons of the past (Donahue, 2006; Coles, 2014).

Prospective standardized methodologies for reporting experiences from major incidents have been proposed and should be used to have comparable data available (Lennquist, 2008) (Fig. 2).

Recommendation: MCIs in mountain areas should be analyzed after the fact and recommendations for changes in practice should be proposed and published. Grade: 1B

Planning and training. Implementation of the previously mentioned principles should be achieved by the development of standard operating procedures (SOPs). SOPs should be activated in case of an MCI (Altevogt et al., 2012). The European Society of Intensive Care Medicine (ESICM) recently focused on urban disaster preparedness. The experts highlighted the value of using written procedures and checklists as well as the importance of training (Joynt et al., 2010). The American College of Chest Physicians (CHEST) also published recommendations: Comprehensive advance planning efforts are considered to be fundamental (Courtney et al., 2014). Written plans should be available. Preparedness is crucial (Lynn et al., 2006; Ben-Ishay et al., 2016).

Training is essential. The European Society for Trauma and Emergency Surgery (ESTES) has developed specific courses in Medical Response to Major Incidents (MRMI) (Lennquist Montan et al., 2014). The importance of training was also highlighted in a study conducted in the U.S. Army (King et al., 2006). Plans may be designed for local purposes and can also be designed to manage international collaboration as required for a given scenario (Vassallo, 2003).

Recommendation: SOPs should be available, well known, and implemented with regular training involving emergency services. Recommendation Grade: 1B

Specific principles of multi-casualty injuries in mountain rescue. Some MCIs are specific to mountain environments.
We identified 38 ski lift accidents involving 1027 people of whom 335 died (Table 3). We also identified 138 avalanche MCIs of which 11 occurred in tourist destinations. Only six of these mountain MCIs have been published in the medical literature, three concerning groups of people struck by lightning (Koch et al., 1997; Carte et al., 2002; Torres, 2004), a ski lift accident (Nicholas and Oberheide, 1988), a mountain train accident (Wildner and Paal, 2015), and one avalanche with 52 casualties (Blancher et al., 2017).

\section{Specific circumstances}

Time, terrain, and weather. The progress of a mountain rescue mission is often determined by natural hazards. In contrast to urban scenarios, rock-fall, avalanches, changes of weather, or visibility have significant impact on MCI management strategy in mountain areas.

Recommendation: Particular attention should be given to time, terrain, and weather. In some situations, rapid extrication and evacuation has priority over medical treatment. Recommendation Grade: 1C

Helicopters. Helicopters may be useful to transport rescue teams on site and to evacuate patients. Helicopters may allow direct access to otherwise inaccessible places; particularly with winching and short-haul operations. In the European Alps, helicopters are widely used for MCIs (Assa et al., 2009; Johnsen et al., 2013) and contribute to saving lives of patients (Bekelis et al., 2015). Guidelines for the use of helicopters in mountain rescue have been published (Tomazin et al., 2003, 2011).

The Chief Commander in cooperation with the Medical Commander must always balance two priorities (1) evacuation of casualties and (2) allocation of medical items and rescuers in the field. Helicopter operations must be coordinated (Johnsen et al., 2016). Small remotely piloted aircraft (drones) have also been used in the mountains and could be helpful during mountain MCIs to have a better overview (Abrahamsen, 2015).

Recommendation: Helicopters with appropriate mountain rescue capabilities are often useful in MCIs. Coordination of helicopter operations is critical. Recommendation Grade: 1B

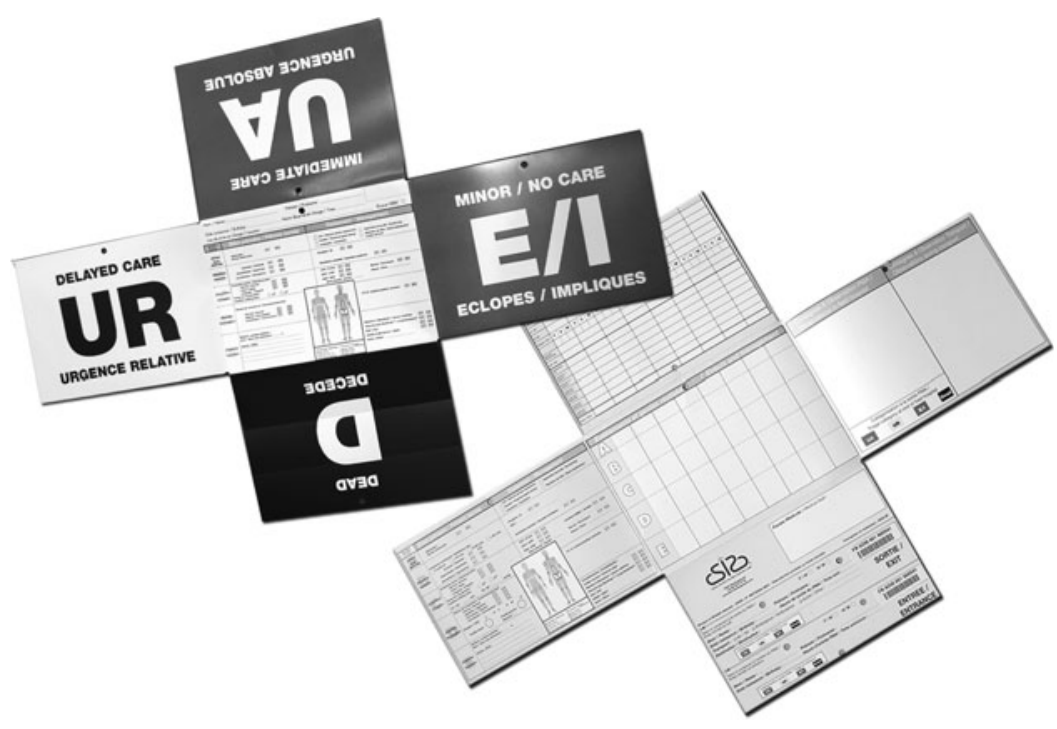

FIG. 2. Example of a dedicated triage card. With authorization from Tanit ${ }^{\circledR}$ company. 
Radio communication. Radio communication among medical teams is a key issue as in any MCI. In the mountains, mobile and telephone networks and radio communication may be limited or unavailable. Reliable communication is essential, because effective medical coordination can save lives. Communications may be difficult when medical teams from different regions or countries are involved, and should be conducted in a language understood by everyone involved (Rimstad and Sollid, 2015; Blancher et al., 2017).

Recommendation: Effective radio communication should be established to enable rapid and detailed transfer of medical information. Recommendation Grade: 1B

Management of uninjured victims. In the mountains, uninjured survivors should be considered as casualties or "walking wounded." Those at risk from the austere environment will often need to be evacuated to a safe and warm place. They may have suffered psychological trauma, may become exhausted and may be at risk of suffering from unexpected exposure to the mountain environment (i.e., hypothermia, dehydration, frostbites). The Chief Commander should be aware of this vulnerable group and include them in the rescue plan.

Recommendation: Uninjured survivors should be considered as casualties at risk in a mountain environment. Recommendation Grade: $1 \mathrm{C}$

Psychological trauma. All casualties, injured or uninjured, may suffer from a prolonged posttraumatic stress syndrome (Peck et al., 1996; Thordardottir et al., 2015). The use of crisis intervention services (CIS) should be considered as soon as possible (Peleg, 2013; Carter and Amlot, 2016).

Recommendation: Immediate or delayed psychological support should be made available to the casualties. Grade: 1C

\section{Specific situations}

Lightning injuries. In contrast to MCIs involving trauma, the rule in lightning injuries is "to resuscitate the dead" (Cooper, 1980; Cooper et al., 2017). This is sometimes referred to as "reverse triage." Lightning can cause sudden death due to cardiac arrest (CA) (Taussig, 1968). Usually, asystole occurs as lightning simultaneously depolarizes all myocardial cells. Ventricular fibrillation has also been reported (Taussig, 1968). Prompt resolution of asystole, due to cardiac automaticity, often results in return of spontaneous circulation (Davis et al., 2014). The medullary respiratory center may, however, be paralyzed for hours. If ventilation is not supported until the victim resumes spontaneous breathing, hypoxic CA is likely. It is generally impossible to resuscitate a victim from hypoxic CA with good neurologic outcome. Ventilatory support may have to be prolonged until return of spontaneous ventilation (Zafren et al., 2005).

Lightning can strike multiple victims simultaneously (Taussig, 1968, 1969; Carte et al., 2002). Lightning victims without vital signs or with circulation but without spontaneous ventilation have an excellent chance of survival if they receive immediate resuscitation (Zafren, 2010). Usually, rescue breathing is all that is required. Lightning victims who are breathing spontaneously are likely to recover without immediate treatment (Cooper, 1980).

Recommendation: Lightning victims who are not breathing and who do not have obvious lethal injuries should be resuscitated before victims who have vital signs. Recommendation Grade: 1B

Avalanches. Avalanche incidents may involve large groups of people (Blancher et al., 2017). Triage criteria for avalanches have been established (Brugger et al., 2013; Paal et al., 2016; Van Tilburg et al., 2017). Unfortunately, these recommendations have not been consistently applied in the field (Strapazzon et al., 2017). In an effort to improve adherence to the guidelines, the ICAR MEDCOM has proposed an Avalanche Resuscitation Checklist (Kottmann et al., 2015).

In MCI avalanches, triage is the key to save as many lives as possible. Different models have been proposed (Bogle et al., 2010; Reiweger et al., 2017). There are three phases in avalanche burial, which require specific rescue strategies.

In the first phase ( $0-35$ minutes after burial), the main priority is to extricate victims as quickly as possible because they are at risk of asphyxia (Brugger et al., 2003; Moroder et al., 2015). In patients with CA, clearing the airway and cardio pulmonary resuscitation (CPR) are critical interventions (Truhlar et al., 2015). If resources are scarce, treatment may need to be limited or withheld to locate victims with a greater chance of survival.

In the second phase (35-60 minutes), patients with unwitnessed CA have very poor outcomes. Medical resources should be concentrated on victims with vital signs unless enough medical personnel are available to treat arrested patients as well (Boue et al., 2014).

In the third phase ( $>60$ minutes), accidental hypothermia is a potential cause of CA. A patient with a clear airway may benefit from prolonged CPR and should be evacuated to a facility offering rewarming using extracorporeal life support (ECLS). Hypothermic survivors should also be treated in an ECLS center if at least one of the following conditions is present; core temperature $<28^{\circ} \mathrm{C}$, ventricular arrhythmia, or systolic blood pressure $<90 \mathrm{mmHg}$ ) (Brown et al., 2012; Paal et al., 2016). Further decisions for initiating ECLS rewarming should be based on the serum potassium level and core temperature (Paal et al., 2016).

Recommendation: For a burial time $<35$ minutes, extrication is the first priority and medical care should focus on victims with signs of life until enough resources are available to treat additional victims in CA. Recommendation Grade: 1B

For burial time 35 to 60 minutes, no CPR should be started on arrested victims unless enough resources are available. Recommendation Grade: 1B

For burial time $>60$ minutes, CPR should only be initiated if the airway is patent. The use of a checklist may improve triage and treatment. Recommendation Grade: 1B

Medical strategy for a group of lost people. Uninjured people lost in a harsh environment may soon become casualties if they cannot protect themselves from extreme climatic conditions. Common situations may be (1) a group of hikers trapped by bad weather, (2) mass gatherings in the mountains, including concerts or sport events, (3) people caught on chair lifts who cannot be extricated quickly, and (4) people on cable cars who need to be guided through difficult terrain.

People tend to leave the site of an incident either to seek help or to improve their situation. This may increase the hazards to some members of groups and may worsen the overall outcome. 
For instance, skiers who jump from stationary chair lifts run a substantial risk of sustaining severe injuries. In all situations, where people are trapped or have been extricated in the wilderness, one must be aware of the risks, such as injuries during evacuation, dehydration, hypothermia, and frostbite. Rescue teams may not know the total number of victims. In a situation in which some mountaineers are lost, a manageable incident may turn into an MCI. Whenever possible, precise information and instructions should be provided to the victims to prevent deterioration of the situation.

Mass gatherings in the mountains require special precautionary medical measures. For instance, festivals may bring thousands of people into remote places. If the weather deteriorates rapidly a large number of hypothermic and panicked victims may require treatment. Sport events, especially endurance competitions in the mountains may quickly lead to dangerous situations for competitors and medical personnel. For example, heat, cold, rain, or snow combined with wind and impaired visibility may require regulations to stop single exhausted competitors or to terminate the entire event (NewsTheLocal, 2008). An experienced clinician and an appropriately sized medical team should be available to supervise and manage casualties.

A qualified medical provider trained in mountain emergency medicine should be deployed with the first rescue team to assess for medical problems, such as heat illness, accidental hypothermia, dehydration, or exhaustion. Illnesses or injuries may not have been reported or appreciated. When arriving at the scene, all victims capable of walking should be assisted to a safe place.

Recommendation: The principles of MCI in mountain areas should be applied to groups of trapped or lost people in harsh mountain environments. Recommendation Grade: 1C

\section{Study limitations}

We acknowledge several limitations: (1) Due to the limited number of medical publications, little information is available regarding these MCIs in mountain areas. Our recommendations mostly rely on expert consensus and empirical knowledge. (2) MCIs in mountain areas from only nine countries were available for this study. This may underestimate the true prevalence of MCIs in mountain areas. Nevertheless, the purpose of this study was not to be exhaustive, but to show that MCIs occur in mountain areas. We excluded plane crashes because unfortunately all identified events had zero survivors and there was no need for medical rescue. Lastly, the number of victims involved in MCIs in mountain areas was not always available and the definition varied from one incident to another, thus numbers may be approximate. The real number of people present during MCI events was probably higher than reported in this study.

\section{Conclusions}

Mountain rescue teams should be prepared to manage MCIs. Knowledge should be reviewed and training performed regularly. Cooperation between terrestrial rescue services, avalanche safety authorities, and helicopter crews is critical to successful management of MCIs in mountain areas.

\section{Acknowledgments}

We would like to thank the ICAR MEDCOM for discussion of the content and EURAC, ICAR, the International
Society of Mountain Medicine (ISMM), the French Mountain Rescue Association (ANMSM), and the French Society of Disaster Medicine (SFMC) for financially supporting the open access publication of this manuscript.

\section{Author Disclosure Statement}

No competing financial interests exist.

\section{References}

Abrahamsen HB. (2015). A remotely piloted aircraft system in major incident management: Concept and pilot, feasibility study. BMC Emerg Med 15:12.

Agresti B. (2013). Mountain Rescuers death during rescue mission, risk analysis. PGHM/CRS; International Commission for Alpine rescue (ICAR). Plain meeting; Bol, Croatia.

Altevogt BM, Stroud C, and Wizemann T. (2012). Barriers to Integrating Crisis Standards of Care Principles into International Disaster Response Plans. Institute of medicine. Workshop summary. The National Academies Press, Washington, DC.

Ammons MA, Moore EE, Pons PT, Moore FA, McCroskey BL, and Cleveland HC. (1988). The role of a regional trauma system in the management of a mass disaster: An analysis of the Keystone, Colorado, chairlift accident. J Trauma 28:1468-1471.

Arcos Gonzalez P, Castro Delgado R, Cuartas Alvarez T, Garijo Gonzalo G, Martinez Monzon C, Pelaez Corres N, Rodriguez Soler A, and Turegano Fuentes F. (2016). The development and features of the Spanish prehospital advanced triage method (META) for mass casualty incidents. Scand J Trauma Resusc Emerg Med 24:63.

Assa A, Landau DA, Barenboim E, and Goldstein L. (2009). Role of air-medical evacuation in mass-casualty incidents-A train collision experience. Prehosp Disaster Med 24:271-276.

Bekelis K, Missios S, and Mackenzie TA. (2015). Prehospital helicopter transport and survival of patients with traumatic brain injury. Ann Surg 261:579-585.

Ben-Ishay O, Mitaritonno M, Catena F, Sartelli M, Ansaloni L, and Kluger Y. (2016). Mass casualty incidents-Time to engage. World J Emerg Surg 11:8.

Blancher M, Bauvent Y, Bare S, Wuyts B, Fillet Y, Brun J, Albasini F, and Bouzat P. (2017). Multiple casualty incident in the mountain: Experience from the Valfrejus avalanche. Resuscitation 111:e7-e8.

Bogle LB, Boyd JJ, and McLaughlin KA. (2010). Triaging multiple victims in an avalanche setting: The Avalanche Survival Optimizing Rescue Triage algorithmic approach. Wilderness Environ Med 21:28-34.

Boue Y, Payen JF, Brun J, Thomas S, Levrat A, Blancher M, Debaty G, and Bouzat P. (2014). Survival after avalancheinduced cardiac arrest. Resuscitation 85:1192-1196.

Bouzat P, Ageron FX, Brun J, Levrat A, Berthet M, Rancurel E, Thouret JM, Thony F, Arvieux C, Payen JF; TRENAU group. (2015). A regional trauma system to optimize the prehospital triage of trauma patients. Crit Care 19:111.

Brown DJ, Brugger H, Boyd J, and Paal P. (2012). Accidental hypothermia. N Engl J Med 367:1930-1938.

Brugger H, Durrer B, Elsensohn F, Paal P, Strapazzon G, Winterberger E, Zafren K, Boyd J, and Icar M. (2013). Resuscitation of avalanche victims: Evidence-based guidelines of the international commission for mountain emergency medicine (ICAR MEDCOM): Intended for physicians and other advanced life support personnel. Resuscitation 84:539-546.

Brugger H, Sumann G, Meister R, Adler-Kastner L, Mair P, Gunga HC, Schobersberger W, and Falk M. (2003). Hypoxia 
and hypercapnia during respiration into an artificial air pocket in snow: Implications for avalanche survival. Resuscitation 58:81-88.

Carte AE, Anderson RB, and Cooper MA. (2002). A large group of children struck by lightning. Ann Emerg Med 39: 665-670.

Carter H, and Amlot R. (2016). Mass Casualty Decontamination guidance and psychosocial aspects of CBRN incident management: A review and synthesis. PLoS Curr 8:1-31.

Chan TC, Killeen J, Griswold W, and Lenert L. (2004). Information technology and emergency medical care during disasters. Acad Emerg Med 11:1229-1236.

Coles E. (2014). Learning the lessons from major incidents: A Short Review of the Literature. Emergency planning college, June 2014, $\mathrm{N}^{\circ} 10$, pp. 19-20.

Cooper MA. (1980). Lightning injuries: Prognostic signs for death. Ann Emerg Med 9:134-138.

Cooper MA, Andrews CJ, Holle RL, Blumenthal R, and Navarette Aldana N. (2017). Lightning-related injuries and safety. In: Auerbach's Wilderness Medicine, 7th ed. P Auerbach. Elsevier, Philadelphia, pp. 71-117.

Courtney B, Hodge JG, Jr., Toner ES, Roxland BE, Penn MS, Devereaux AV, Dichter JR, Kissoon N, Christian MD, Powell T; Task Force for Mass Critical Care; Task Force for Mass Critical Care. (2014). Legal preparedness: Care of the critically ill and injured during pandemics and disasters: CHEST consensus statement. Chest 146:e134S-e144S.

Culley JM, Svendsen E, Craig J, and Tavakoli A. (2014). A validation study of 5 triage systems using data from the 2005 Graniteville, South Carolina, chlorine spill. J Emerg Nurs 40: 453-460.

Davis C, Engeln A, Johnson EL, McIntosh SE, Zafren K, Islas AA, McStay C, Smith WR, Cushing T, and Wilderness Medical S. (2014). Wilderness Medical Society practice guidelines for the prevention and treatment of lightning injuries: 2014 update. Wilderness Environ Med 25:S86-S95.

Donahue AK. (2006). Lessons We don't learn a study of the lessons of disasters, why we repeat them, and how we can learn them. Homeland Security Affairs, vol II, No. 2.

Fattah S, Rehn M, Reierth E, and Wisborg T. (2013). Systematic literature review of templates for reporting prehospital major incident medical management. BMJ Open 3:1-8.

FEMA. The national incident management system. Federal emergency management agency. The US department of Homeland security. www.fema.gov/national-incident-management-system (last accessed November 9, 2017).

Freitas RL. (2016). Scene safety and situational awareness in disaster response. In: Ciottone's Disaster Medicine, 2nd ed. Elsevier, Philadelphia, Chapter 39, pp. 255-262.

Frykberg ER. (2002). Medical management of disasters and mass casualties from terrorist bombings: How can we cope? J Trauma 53:201-212.

Garrison HG. (2002). Keeping rescuers safe. Ann Emerg Med 40:633-635.

Guéant C. (2011). Circulaire du 6 juin 2011 relative aux orientations générales pour la mise en oeuvre des moyens publics concourante au secours en montagne et sa formalisation dans le cadre d'une disposition spécifique ORSEC. French Mininisrty of the Interior.

Guyatt G, Gutterman D, Baumann MH, Addrizzo-Harris D, Hylek EM, Phillips B, Raskob G, Lewis SZ, and Schunemann H. (2006). Grading strength of recommendations and quality of evidence in clinical guidelines: Report from an american college of chest physicians task force. Chest 129: 174-181.
Hammond J. (2005). Mass casualty incidents: Planning implications for trauma care. Scand J Surg 94:267-271.

Haverkort JJ, Bouman JH, Wind JD, and Leenen LP. (2016). Continuous development of a major incident in-hospital victim tracking and tracing system, withstanding the challenges of time. Disaster Med Public Health Preparedness 2017;11:244-250

Johnsen AS, Fattah S, Sollid SJ, and Rehn M. (2013). Impact of helicopter emergency medical services in major incidents: Systematic literature review. BMJ Open 3:e003335.

Johnsen AS, Fattah S, Sollid SJ, Rehn M. (2016). Utilisation of helicopter emergency medical services in the early medical response to major incidents: A systematic literature review. BMJ Open 6:e010307.

Joynt GM, Loo S, Taylor BL, Margalit G, Christian MD, Sandrock C, Danis M, Leoniv Y, and Sprung CL, European Society of Intensive Care Medicine's Task Force for intensive care unit triage during an influenza epidemic or mass disaster. (2010). Chapter 3. Coordination and collaboration with interface units. Recommendations and standard operating procedures for intensive care unit and hospital preparations for an influenza epidemic or mass disaster. Intensive Care Med 36 Suppl 1:S21-S31.

Keim ME. (2016). Disaster Preparedness. In: Ciottone's Disaster Medicine, 2nd edition. Elsevier, Philadelphia, Chapter 32, pp. 200-214.

Kilner TM, Brace SJ, Cooke MW, Stallard N, Bleetman A, and Perkins GD. (2011). In 'big bang' major incidents do triage tools accurately predict clinical priority?: A systematic review of the literature. Injury 42:460-468.

King DR, Patel MB, Feinstein AJ, Earle SA, Topp RF, Proctor KG. (2006). Simulation training for a mass casualty incident: two-year experience at the Army Trauma Training Center. J Trauma 61:943-948.

Koch FX, Torres J, Godart J, Escallier C, and Menthonnex E. (1997). Accident catastrophique à effets limités de niveau 1 en montagne: à propos d'un cas de fulguration collective. French society of disaster medicine. Volume XVI, pp. 103-107.

Kottmann A, Blancher M, Spichiger T, Elsensohn F, Letang D, Boyd J, Strapazzon G, Ellerton J, and Brugger H. (2015). The Avalanche Victim Resuscitation Checklist, a new concept for the management of avalanche victims. Resuscitation 91: e7-e8.

Lennquist S. (2008). Protocol for reports from major accidents and disasters in the International Journal of Disaster Medicine. Eur J Trauma Emerg Surg 34:486-492.

Lennquist Montan K, Hreckovski B, Dobson B, Ortenwall P, Montan C, Khorram-Manesh A, and Lennquist S. (2014). Development and evaluation of a new simulation model for interactive training of the medical response to major incidents and disasters. Eur J Trauma Emerg Surg 40:429-443.

Lerner EB, McKee CH, Cady CE, Cone DC, Colella MR, Cooper A, Coule PL, Lairet JR, Liu JM, Pirrallo RG, Sasser SM, Schwartz R, Shepherd G, and Swienton RE. (2015). A consensus-based gold standard for the evaluation of mass casualty triage systems. Prehosp Emerg Care 19:267-271.

Loriette JJ. (2015). Germanwins. Plane crash. PGHM-UCTM; International commission for alpine rescue (ICAR). Plain meeting Killarney, Rep of Ireland.

Lynn M, Gurr D, Memon A, and Kaliff J. (2006). Management of conventional mass casualty incidents: Ten commandments for hospital planning. J Burn Care Res 27:649-658.

Maguire BJ, Hunting KL, Smith GS, and Levick NR. (2002). Occupational fatalities in emergency medical services: A hidden crisis. Ann Emerg Med 40:625-632. 
Marres GM, Taal L, Bemelman M, Bouman J, and Leenen LP. (2013). Online Victim Tracking and Tracing System (ViTTS) for major incident casualties. Prehosp Disaster Med 28:445-453.

Moroder L, Mair B, Brugger H, Voelckel W, and Mair P. (2015). Outcome of avalanche victims with out-of-hospital cardiac arrest. Resuscitation 89:114-118.

NewsTheLocal. (2008). Two runners dead after storm overtakes extreme Zugspitze race. In The Local. www.thelocal.de/ 20080714/13051 (last accessed November 9, 2017).

Nicholas RA, and Oberheide JE. (1988). EMS response to a ski lift disaster in the Colorado mountains. J Trauma 28:672-675.

Paal P, Gordon L, Strapazzon G, Brodmann Maeder M, Putzer G, Walpoth B, Wanscher M, Brown D, Holzer M, Broessner $\mathrm{G}$, and Brugger H. (2016). Accidental hypothermia-an update: The content of this review is endorsed by the International Commission for Mountain Emergency Medicine (ICAR MEDCOM). Scand J Trauma Resusc Emerg Med 24: 111.

Peck DF, Robertson A, and Zeffert S. (1996). Psychological sequelae of mountain accidents: A preliminary study. J Psychosom Res 41:55-63.

Peleg K. (2013). Disaster and emergency medicine-A conceptual introduction. Front Public Health 1:44.

Price CL, Brace-McDonnell SJ, Stallard N, Bleetman A, Maconochie I, and Perkins GD. (2016). Performance characteristics of five triage tools for major incidents involving traumatic injuries to children. Injury 47:988-992.

Reiweger I, Genswein M, Paal P, and Schweizer J. (2017). A concept for optimizing avalanche rescue strategies using a Monte Carlo simulation approach. PLoS One 12:e0175877.

Rimstad R, and Sollid SJ. (2015). A retrospective observational study of medical incident command and decision-making in the 2011 Oslo bombing. Int J Emerg Med 8:4.

Sacco WJ, Navin DM, Fiedler KE, Waddell RK, 2nd, Long WB, and Buckman RF, Jr. (2005). Precise formulation and evidence-based application of resource-constrained triage. Acad Emerg Med 12:759-770.

Strapazzon G, Plankensteiner J, Mair P, Ruttmann E, Dal Cappello T, Procter E, and Brugger H. (2017). Prehospital management and outcome of avalanche patients with out-ofhospital cardiac arrest: A retrospective study in Tyrol, Austria. Eur J Emerg Med 24:398-403.

Taussig HB. (1968). "Death" from lightning-And the possiblity of living again. Ann Intern Med 68:1345-1353.

Taussig HB. (1969). "Death" from lightning and the possibility of living again. Am Sci 57:306-316.

Thordardottir EB, Valdimarsdottir UA, Hansdottir I, Resnick H, Shipherd JC, and Gudmundsdottir B. (2015). Posttraumatic stress and other health consequences of catastrophic avalanches: A 16-year follow-up of survivors. J Anxiety Disord 32:103-111.

Tomazin I, Ellerton J, Reisten O, Soteras I, Avbelj M; International Commission for Mountain Emergency M. (2011). Medical standards for mountain rescue operations using helicopters: Official consensus recommendations of the International Commission for Mountain Emergency Medicine (ICAR MEDCOM). High Alt Med Biol 12:335-341.

Tomazin I, Kovacs $\mathrm{T}$, and International Commission for Mountain Emergency M. (2003). Medical considerations in the use of helicopters in mountain rescue. High Alt Med Biol 4:479-483.

Torres B. (2004). MCI in the clouds: The beauty of the clouds $\&$ terrain of the Grand Teton masks the obstacles rescuers faced in the response, care $\&$ transport of multiple victims of a lightning strike. JEMS 29:34-36, 38, 40 passim.

Truhlar A, Deakin CD, Soar J, Khalifa GE, Alfonzo A, Bierens JJ, Brattebo G, Brugger H, Dunning J, Hunyadi-Anticevic S, Koster RW, Lockey DJ, Lott C, Paal P, Perkins GD, Sandroni $\mathrm{C}$, Thies KC, Zideman DA, Nolan JP; Cardiac arrest in special circumstances section Collaborators. (2015). European Resuscitation Council Guidelines for Resuscitation 2015: Section 4. Cardiac arrest in special circumstances. Resuscitation 95: 148-201.

Van Tilburg C, Grissom CK, Zafren K, McIntosh S, Radwin MI, Paal P, Haegeli P, Smith WW, Wheeler AR, Weber D, Tremper B, and Brugger H. (2017). Wilderness Medical Society Practice guidelines for prevention and management of avalanche and nonavalanche snow burial accidents. Wilderness Environ Med 28:23-42.

Vassallo J. (2003). Combined UK/US field hospital management of a major incident arising from a chinook helicopter crash in Afghanistan, 28 Jan 2002. J R Army Med Corps 149:47-52.

Vassallo J, Horne S, Ball S, and Whitley J. (2014). UK Triage the validation of a new tool to counter an evolving threat. Injury 45:2071-2075.

Wildner M, and Paal P. (2015). A large-scale accident in Alpine terrain. Med Klin Intensivmed Notfmed 110:21-26.

Zafren K. (2010). Avalanche triage: Are two birds in the bush better than one in the hand? Wilderness Environ Med 21:273274; author reply 274-276.

Zafren K, Durrer B, Herry JP, Brugger H, Icar, and Uiaa M. (2005). Lightning injuries: Prevention and on-site treatment in mountains and remote areas. Official guidelines of the International Commission for Mountain Emergency Medicine and the Medical Commission of the International Mountaineering and Climbing Federation (ICAR and UIAA MEDCOM). Resuscitation 65:369-372.

Address correspondence to: Marc Blancher, MD Emergency Department Centre Hospitalier Universitaire Grenoble-Alpes Grenoble F-38043

France

E-mail: mblancher@chu-grenoble.fr

Received November 10, 2017; accepted in final form January 5, 2018. 